\title{
Hybridisation of battery, supercapacitor and hybrid capacitor for load applications with high crest factors: a case study of electric vehicles
}

\author{
Immanuel N. Jiya ${ }^{1}$, Nicoloy Gurusinghe ${ }^{2}$, Rupert Gouws ${ }^{3}$ \\ ${ }^{1,3}$ North-West University, South Africa \\ ${ }^{2}$ Queen's University Belfast, United Kingdom
}

\begin{tabular}{l}
\hline Article Info \\
\hline Article history: \\
Received Oct 1, 2018 \\
Revised Dec 10, 2018 \\
Accepted Jan 25, 2019 \\
\hline Keywords: \\
DC-DC converter \\
Electric vehicle \\
Energy storage \\
Hybridization \\
Hybrid capacitor \\
Supercapacitor \\
\hline
\end{tabular}

\begin{abstract}
This paper proposes a novel topology of hybridizing battery, supercapacitor and hybrid capacitor for optimum utilization of energy in electric vehicles. Hybridization of energy storage has been the theme of much research in the field of power electronics as it is an effective economic solution towards improving the utilization of energy. This paper deals with the combination of both supercapacitor and hybrid capacitor with the battery thus addressing the problem of the lack of autonomy between two recharge points in supercapacitors. The prospects of using a multiple-input DC-DC converter is also analyzed. An experimental electric vehicle profile was used to verify the proposed topology and the results are presented. The application of the novel hybridization of the three energy storage devices can be extended to other applications having a load profile with high crest factors.
\end{abstract}

Copyright $@ 2019$ Institute of Advanced Engineering and Science. All rights reserved.

\section{Corresponding Author:}

Jiya Immanuel Ninma,

North-West University,

South Africa.

Email: immanueljiya@ieee.org

\section{INTRODUCTION}

The effects and threats of global warming to the world have driven the increased development of highly efficient and environmentally friendly alternative source of energy for use. This has fueled the researches into renewable energy sources for both domestic and industrial use [1-4]. Energy storage seems to be the biggest challenge in the advancement towards renewable energy solutions. hybridization of energy storage has been the theme of much research in this field [5-7]; therefore, it is an effective economic solution towards improving the performance of renewable energy systems.

The automotive industry is not left out in the mandate for use of green energy as calls for reduced carbon emissions have resulted in the growing number of electric vehicle manufacturers [8-10]. Reports, however, indicate that in most of the electric vehicles in use today, the ratio of power to energy P/E in the energy storage of these vehicles is approximately 8:1 [11]. This indicates that the storage systems, which is mostly battery cells, are designed for power dense operations rather than the energy dense operations performed by the vehicle (that is the anticipated peak power rather than for efficient energy use) [12]. This wide ratio is because electric vehicles require high power during acceleration, hence the oversizing of the batteries. To augment for this high power density requirement in electric vehicles, a hybridization of energy storage is required, since batteries are energy dense.

The Current surges drawn from the batteries resulting from the high crest factor load profiles, caused by the repeated acceleration and deceleration of electric vehicles lead to an increase in the internal resistance of the battery [13]. This will, in turn, reduce the efficiency of the battery and also results in premature failure of the battery. An example of this phenomenon is in Figure 1(a) and Figure 1(b), the 
Worldwide harmonized Light vehicles Test Cycle and its corresponding effect on a battery storage system is presented as reported in [14]. The test cycle is divided into two sequences, each sequence lasting for a period of 15 minutes, the first sequence is a period of urban driving while the second is a period of extra-urban or highway driving, from Figure 1(b) the corresponding effects of the just described driving cycle on an energy storage system is seen. The effect of the repeated acceleration and deceleration is very detrimental to the efficiency and lifespan of a battery only energy storage system. Much work has been done in literature as regards the hybridization of batteries and supercapacitors (SCs). Although SCs have high power density, they still pose a disadvantage as they limit average autonomy between two recharge points; this is due to their poor energy densities [15].

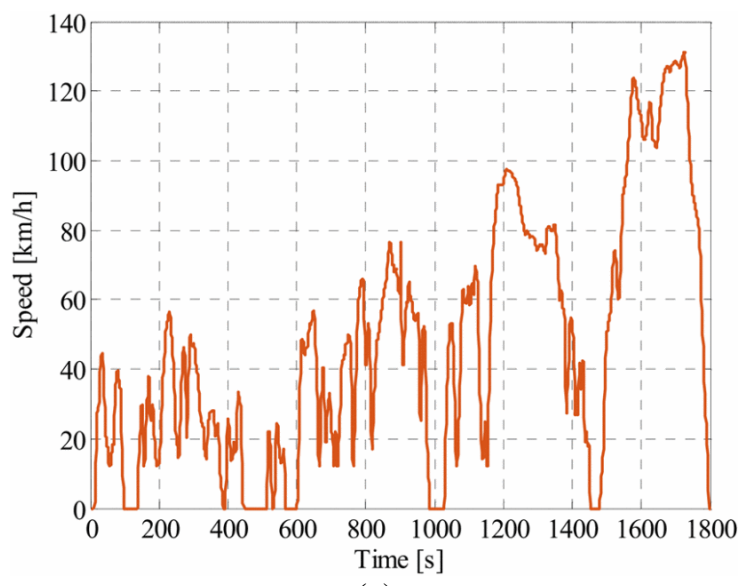

(a)

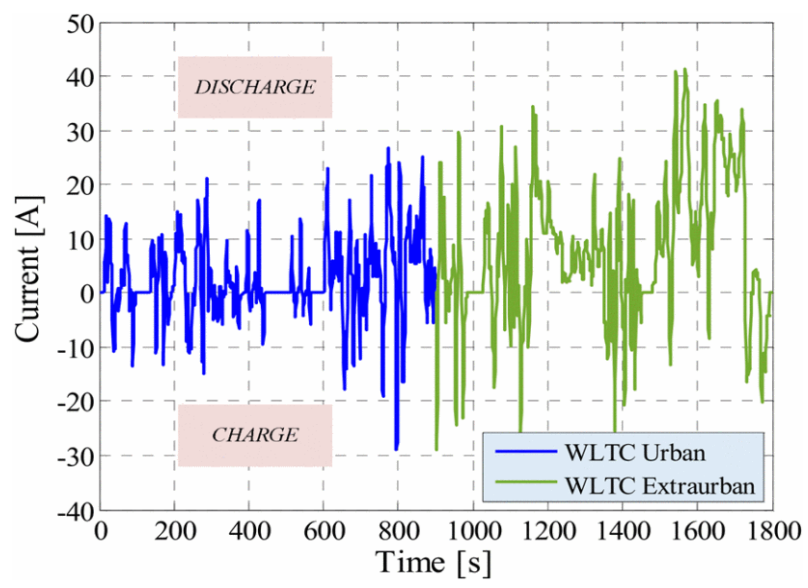

(b)

Figure 1. Graph of (a) the Worldwide harmonized Light vehicles Test Cycle (WLTC) and

(b) the corresponding effect of the drive cycle on an energy storage system [14]

Lithium-ion capacitors, otherwise known as hybrid capacitors (HCs) have received attention in recent researches. They tend to lie in the mid-point between SCs and batteries [15]. This is because they have higher energy densities than SCs, though not as much as batteries, but higher power densities than batteries and lower power densities than SCs. SCs and HCs especially, pose great advantages in energy harvesting through regenerative braking because of their ability to accept and dissipate large currents during charging and discharging $[15,16]$. Batteries have fallen short in comparison to both SCs and HCs in the aspect of high power delivery. Batteries also have a limited charge and recharge cycle; this gives the SCs and the HCs an advantage in their application for electric vehicles especially since regenerative braking occurs quite frequently in the driving cycle.

The lack of a single energy storage solution to the energy and power requirement of electric vehicles is the motivation of this paper [1]. Less work has been done to combine batteries and HCs as compared to SCs [17], this most likely is as a result of the high cost of hybrid capacitor devices. All of the work done in the aspect of hybridization of energy storages as regards supercapacitors and hybrid capacitors has been to explore either of the two devices. However, the two devices have varying characteristics lying on two extremes, (the SC having a much higher power density than the $\mathrm{HC}$ while the $\mathrm{HC}$ having a much higher energy density than the SC). This leaves a gap in the midpoint between the high power density of SCs and the high energy density of HCs, because the SCs have a low energy density, during regenerative braking, not all the energy can be fully stored up in the SCs while the HCs have much lower power densities, therefore, they cannot cater for the high power dense operations in the vehicle drive cycle. The application of hybridised energy storage systems cannot be overemphasized. It finds relevance in a wide area of applications ranging from DC Microgrids to electric vehicles of any kind [18]. Generally any electric system with a load curve having high ramp rates (as is seen in Figure 1(b); the high crest factors in the load curve of these systems calls for a hybridised storage since it would not be economical to design batteries solely for the peak power applications.

In this paper, the hybridization of batteries, SCs and $\mathrm{HCs}$ is carried out; this is to exploit their individual advantages in order to close the gap between the high power density of SCs, their low energy densities and vice-versa for HCs. A multiple-input DC-DC converter is analysed for implementation with the proposed converter. A section that addresses the modelling of the components is included, results are 
presented to validate the proposed topology, and experimental data from previous research is used to validate the proposed topology.

\section{ENERGY STORAGE MODELLING AND PARAMETER IDENTIFICATION}

The performance characteristics of energy storage devices in automotive power applications can be described using two parameters namely power density (or specific power) and energy density (or specific energy) [19]. The power density is related to the vehicles speed and acceleration, it more or less determines how fast the vehicle can go. The energy density, on the other hand, relates to the range of the vehicle, i.e. how far the vehicle can go. The relationship of this two performance characteristics when plotted on a graph is called the Ragone plot.

It can be seen from the Ragone plot presented in Figure 2 [20] that, the batteries especially the Liion based batteries lie on the very high energy density axis making them very suitable for high energy density operations in the driving cycle of a vehicle. The HCs (Li-ion capacitors) lie on the high energy density and slightly high power dense axis, comparing them to the SCs, the SCs have much better power densities making the SC most suitable for high power dense operations in the drive cycle. Considering these performance characteristics, the three energy storage devices used in this research is proposed in order to adequately deliver power to the electric vehicle. The battery would be used to cater for the high energy dense operations, the SC and $\mathrm{HC}$ to cater for high power dense operations while also providing enough storage space to capture the energy generated during regenerative braking. In order to accurately simulate the electrical behaviour of the components in a software environment, it is important to correctly use the electrical models of the components in order to get an accurate view of their electrical behaviour in response to a load. The the models of the battery bank, SC and HC bank and the load used were as described and used in [21], more detail on the models of supercapacitors can be found in [7].

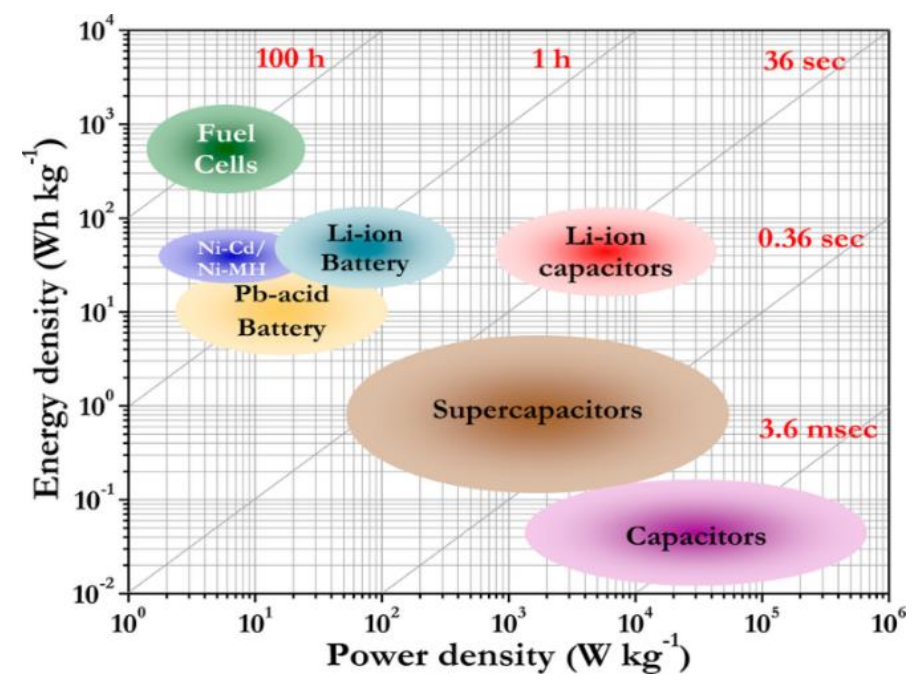

Figure 2. Ragone plot showing, Lithium battery, SCs and HCs [20]

The validation of the hybridization topologies presented in this paper was done with the Matlab® Simulink ${ }^{\circledR}$ software using the parameters presented in Table 1 and used in [21], these parameters were obtained from the respective datasheets [22-24]. The SC cells used were the Maxwell technologies' K2 series, the BCAP2000 P270. The HC cells were the JM Energy Corporation's CPP3300S Lithium-ion capacitor. These SC and HC cells were selected in such a way that they have matching sizes, both in weight and volume. The battery used was the Lead Crystal Batteries' 6-CNFJ-200 series; this size of battery cell was selected so that the energy drawn out of it during the simulation was insignificant as compared to the total energy stored in it. The value of the discharge resistance $(\mathrm{Rp})$ is not presented for the hybrid capacitor. This is because the value of the leakage current was not presented in the datasheet, however, since this is a short duration study, the effects of the leakage resistance is insignificant. 
Table 1. Parameter Identification for the Experiment $[22,23,25]$

\begin{tabular}{|c|c|c|}
\hline Device & Parameter & Value \\
\hline \multirow{5}{*}{ Supercapacitor [25] } & $E S R\left(E S R_{T}\right)$ & $0.35 \mathrm{~m} \Omega(0.58 \mathrm{~m} \Omega)$ \\
\hline & cell voltage (max. bank voltage) & $2.7 \mathrm{~V}(13.5 \mathrm{~V})$ \\
\hline & cell capacitance $\left(C_{T}\right)$ & $2000 \mathrm{~F}(1200 \mathrm{~F})$ \\
\hline & max. energy in bank & $30.375 \mathrm{Wh}$ \\
\hline & $R p\left(R p_{T}\right)$ & $642 \Omega(3210 \Omega)$ \\
\hline \multirow{4}{*}{ Hybrid capacitor [22] } & $\operatorname{ESR}\left(E S R_{T}\right)$ & $0.7 \mathrm{~m} \Omega(2.8 \mathrm{~m} \Omega)$ \\
\hline & cell voltage (max. bank voltage) & $3.8 \mathrm{~V}(15.2 \mathrm{~V})$ \\
\hline & cell capacitance $\left(C_{T}\right)$ & $3300 \mathrm{~F}(825 \mathrm{~F})$ \\
\hline & $\begin{array}{c}\max . \text { energy in bank } \\
R p\left(R p_{T}\right)\end{array}$ & $\begin{array}{c}26.47 \mathrm{Wh} \\
*\end{array}$ \\
\hline \multirow{3}{*}{ Battery [23] } & rated voltage & $12 \mathrm{~V}$ \\
\hline & capacity & $200 \mathrm{Ah}$ \\
\hline & internal resistance $(R i)$ & $3.5 \mathrm{~m} \Omega$ \\
\hline
\end{tabular}

*This data could not be obtained, as the value of the leakage current was not presented in the datasheet

The next step towards selecting the component was to determine the minimum appropriate $\mathrm{M} \mathrm{x} \mathrm{N}$ ( $\mathrm{M}=$ number of cells in series and $\mathrm{N}=$ number of series cells in parallel) matrix configuration for the $\mathrm{SC}$ and $\mathrm{HC}$ banks. The cells were stacked in series to achieve a minimum of $12 \mathrm{~V}$, which is the nominal voltage of the battery. For the SCs, 5 cells of $2.7 \mathrm{~V}$ each would be required to have a minimum of $12 \mathrm{~V}$ and 4 cells of $3.8 \mathrm{~V}$ each is required to meet the minimum required voltage level for the HCs. The matrix configuration for the SC bank was $5 \times 3$ while that of the $\mathrm{HC}$ bank was $4 \times 1$. The reason for having 3 sets of series stacked cells in the supercapacitors as opposed to 1 set of series stacked cells in the hybrid capacitor is to have about the same amount of energy storage capacity in both banks. The difference between the energy stored in both banks is about $3 \mathrm{Wh}$. If fewer sets of SCs are used, the equivalent series resistance, which directly affects the power density, is increased, therefore, making it less power dense and if more HCs are used, its equivalent series resistance reduces, but the cost of energy $\$ / \mathrm{kWh}$ becomes significantly higher. Therefore, the optimal ratio of SCs to HCs for this application is 3 to 1 .

\section{NEW HYBRIDISATION TECHNIQUE}

There are three main techniques of energy storage hybridisation and they are: direct hard wiring of the three energy storage devices, the second is hybridization by individual power controllers in the form of DC-DC converters and the last technique, which is the novel contribution of this paper, involves parallel configuration of $\mathrm{HC}$ and $\mathrm{SC}$ while sharing a power controller in combination with the battery pack through DC-DC converters.

The first hybridization technique is simple but it is also inefficient due to the autonomy in their energy supply, therefore the need to control the energy supplied from the devices cannot be overemphasized. Also, the use of individual controllers for each energy storage as presented in [21] is still cumbersome even when the multiple-input converter was introduced, the number of switches is many and the complexity of the control is tedious due to the many available options. To reduce the number of switches, simplify the control, reduce the cost and size of the multiple-input converter, a novel technique of hybridizing the three energy storages is being introduced here. In this technique, two of the three energy storages are connected directly but are then connected with the third one through DC-DC converters. This is illustrated in Figure 3; the SC and $\mathrm{HC}$ are connected directly in parallel then hybridized with the battery through DC-DC converters. The justification for this is; since the $\mathrm{SC}$ and $\mathrm{HC}$ both have high power densities and lower energy densities than the batteries, their internal resistances is sufficient to divide the load current among them.

Figure 4 shows the response of the SC and HC to the load profile used in Figure 4, when they are both connected in parallel without their individual DC-DC converters. The HC was charged up to the voltage level of the SC. In Figure 4, it can be seen that in both load profiles, the SC supplies the higher currents, this is because it has a lower internal resistance, hence a higher power density than the HC. However, because of it's lower energy density, and higher power density than the HC, in Figure 4(a), at about 6 seconds just after the ramp, SC drops below the $\mathrm{HC}$ and supplies less current than the HC. This is due to the dip in the voltage of the SC, the moment it charges up to the same voltage level with the $\mathrm{HC}$, it picks up again to supply the higher currents. This charging and recharging phenomenon is an acceptable tradeoff because the SC and HC both have a very high charge-discharge cycle. These results show that even without the SC and HC being connected to their individual DC-DC converters or individual ports of a multiple input converter, there is a balanced sharing of load currents between them when they are connected in parallel directly. 


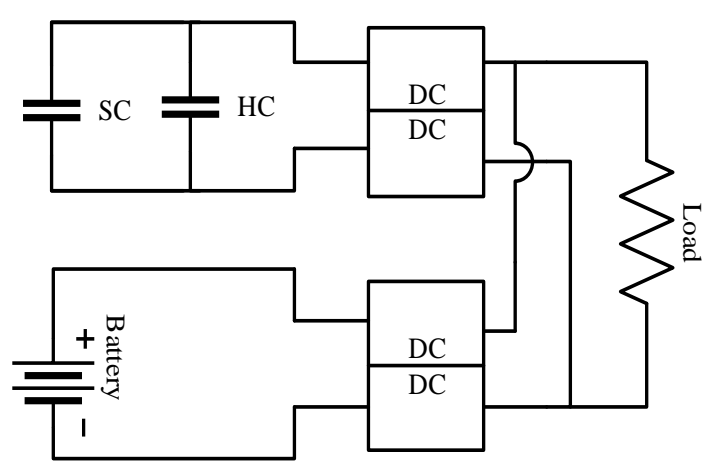

Figure 3. Schematic of the proposed technique of energy storage hybridization having the supercapacitor and hybrid capacitor connected in parallel

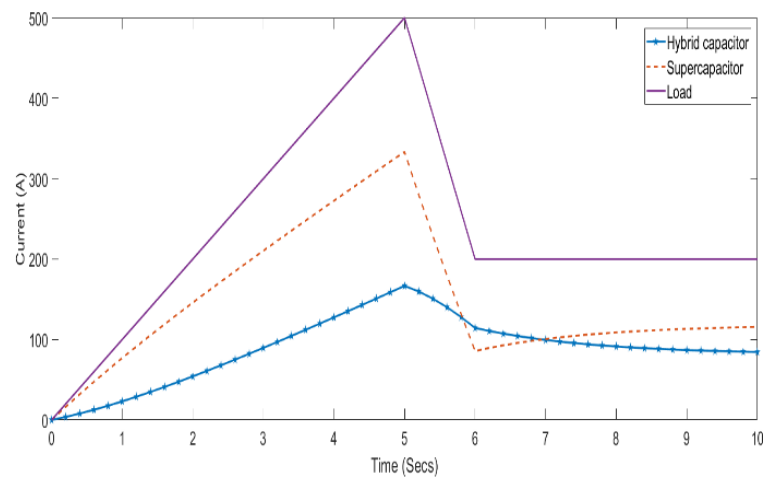

(a)

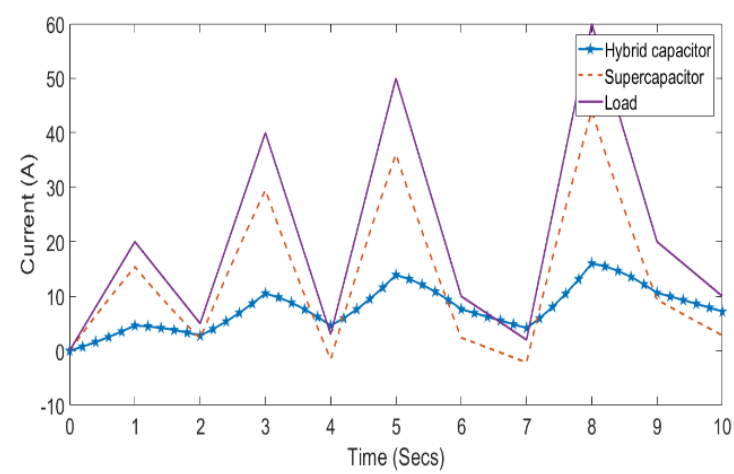

(b)

Figure 4. Response of supercapacitor and hybrid capacitor when they are connected directly in parallel, having (a) a load profile having a ramp from rest signifying acceleration then followed up by a constant current signifying constant speed and (b) a load profile having several ramps

Therefore, the extra DC-DC converter or extra port that would have been dedicated to each can be removed thereby reducing the number of switches, the resulting converter that is required is presented in Figure 5. The reliability and efficiency of the system is increased and switching losses reduced because the part count of the converter is reduced from 12 pieces to 10 . This hybridization technique is characterized by about $65 \%$ controllability as regards to which energy storage device is supplying the required energy to the electric vehicle at any given time. Aside from reducing the number of resources to be spent on the power electronics in the previously discussed hybridization technique, this technique will also reduce the complexity of the control of the multiple-input converter since only two ports are present. The converter will operate in modes A - D as described in Table 2, when the energy storage devices are supplying energy and when the DC link is supplying energy to the storage devices during regenerative braking respectively. The steady-state waveform of the converter operation is presented in Figure 6, the relationship between the battery voltage and DC bus voltage in mode A and D is presented in (1) and (2). The relationship between the DC bus voltage and the parallel arrangement of SC and $\mathrm{HC}$ is given by (3) and (4) for modes B and C respectively.

$$
\begin{aligned}
& V_{d c}=\frac{T 1}{T 2+T 3} \cdot V_{B}=\frac{D}{1-D} \cdot V_{B} \\
& V_{B}=\frac{T 1}{T 2+T 3} \cdot V_{d c}=\frac{D}{1-D} \cdot V_{d c} \\
& V_{d c}=\frac{T 1}{T 2+T 3} \cdot \frac{1}{2}\left(V_{S C}+V_{H C}\right)=\frac{D}{1-D} \cdot \frac{1}{2}\left(V_{S C}+V_{H C}\right) \\
& \frac{1}{2}\left(V_{S C}+V_{H C}\right)=\frac{T 1}{T 2+T 3} \cdot V_{d c}=\frac{D}{1-D} \cdot \frac{1}{2} V_{d c}
\end{aligned}
$$




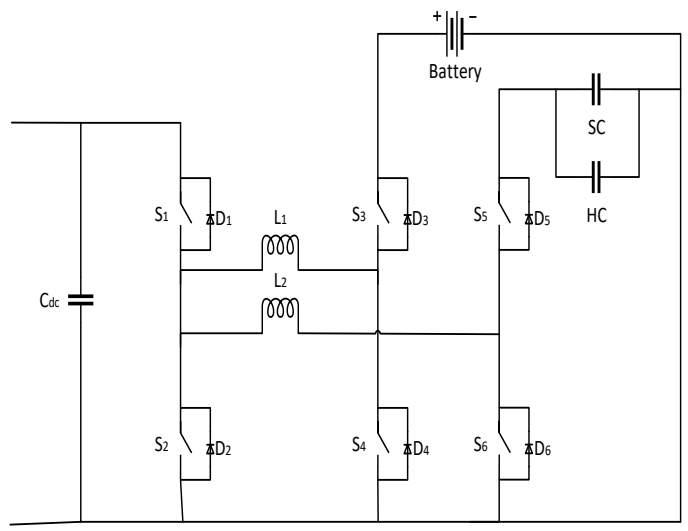

Table 2. Conduction of devices for the operation modes of the converter with $\mathrm{HC}$ and SC sharing one input port

\begin{tabular}{lccc}
\hline & $T_{1}$ & $T_{2}$ & $T_{3}$ \\
\hline Mode A & $S_{3} S_{2}$ & $D_{1} D_{4}$ & $S_{1} S_{4}$ \\
Mode B & $S_{5} S_{2}$ & $D_{1} D_{6}$ & $S_{1} S_{6}$ \\
Mode C & $S_{1} S_{4}$ & $D_{2} D_{3}$ & $S_{2} S_{3}$ \\
Mode D & $S_{1} S_{6}$ & $D_{2} D_{5}$ & $S_{2} S_{5}$ \\
\hline
\end{tabular}

Figure 5. The proposed hybridization topology using two inputs having the supercapacitor and hybrid capacitor connected together in parallel then in series

to one input port while the battery takes the other input port

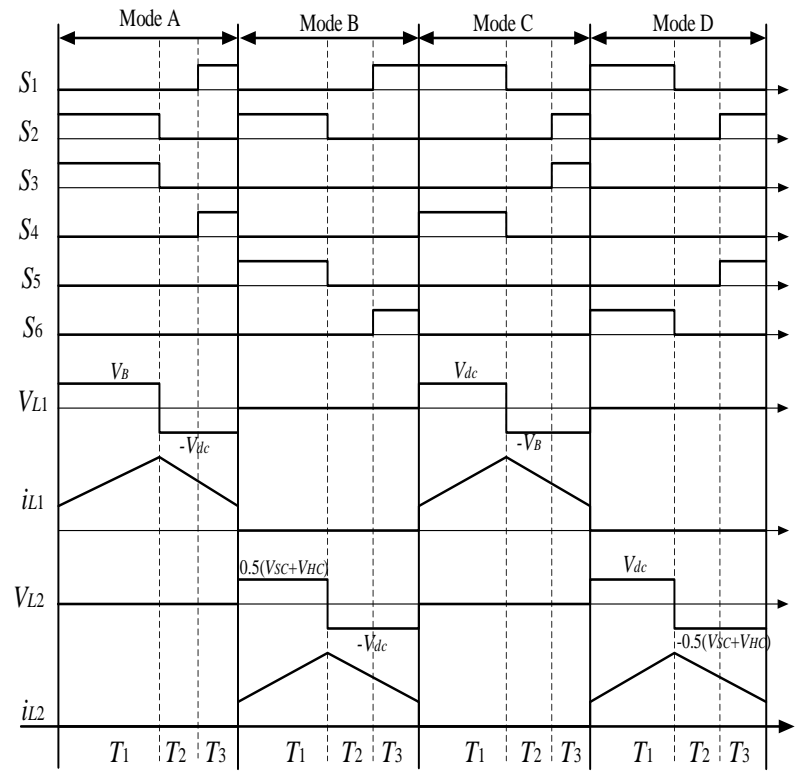

Figure 6. Steady state waveforms of the operation modes of multiple input converter with $\mathrm{HC}$ and $\mathrm{SC}$ having common input port

\section{RESULTS}

To further validate this hybridization topology, the experimental results obtained by [25] in their research which involved the combination of battery, SCs and Fuel cells was used to compare the performance of the individual controller topology to the novel topology proposed in this research. Figure 7(a) is the load profile obtained from their experiment, the areas shaded green represent a period of increasing speed of the electric vehicle, the purple region is for when the vehicle moves at constant speed, the red region represents a period of acceleration where the vehicle overtakes another vehicle and finally the yellow region represents when the vehicle is decelerating. This load profile closely represents all the major events that occur in the driving cycle of a vehicle. In Figure 7(b) a summary of the results obtained in their research is presented. They first tried to use each of the three energy storages (i.e. Fuel cells, Supercapacitors and Batteries) individually and two in combination to evaluate their performances but the authors reported that the best performances were obtained when all the three energy storage devices were hybridised together. 


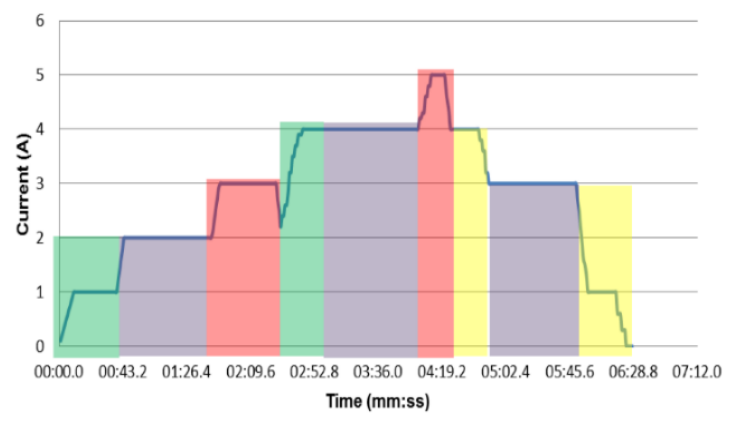

(a)

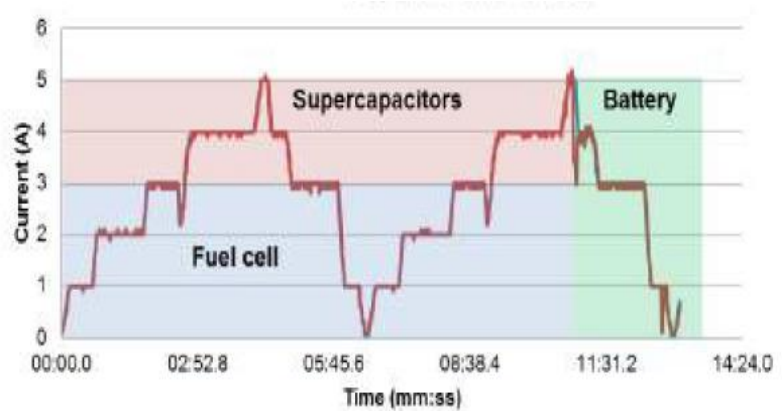

(b)

Figure 7. Graph of (a) the realistic load profile obtained from the electric mine vehicle and (b) the response of Fuel cell, Supercapacitors and the Battery to the load profile presented in (a) [25]

The load profile they obtained was used to compare the performances of HCs, SCs and battery hybridized together using a different control strategy as is proposed in this paper and the results are presented in Figure 8. The topology of each energy storage is presented in Figure 8(a), comparing 15 (a) to 15 (b) It is observed that power is still adequately delivered to the load in Figure 8(b) in which the novel hybridization topology is implemented, therefore, the proposal that the SCs and HCs do not need to each have individual controllers is validated. In both Figure 8(a) and Figure 8(b), it can be observed that the battery at rest almost throughout the driving cycle, this is because the control strategy applied here. It was designed such that all current requirement from the load that exceeded $2 \mathrm{~A}$ is supplied by either the HC or SC, depending on if they had an individual controller or were both hardwired together. It can also be observed that the load profile used has a peak current value of only $5 \mathrm{~A}$ which is far smaller than the $60 \mathrm{~A}$ in Figure 4 and Figure 4, therefore the control strategy was scaled down appropriately to reflect the reduction of the current in the load profile used for the experimentation.

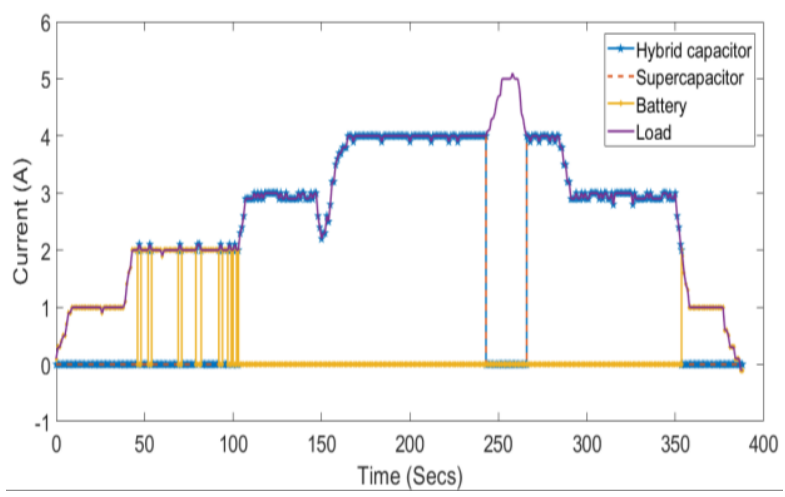

(a)

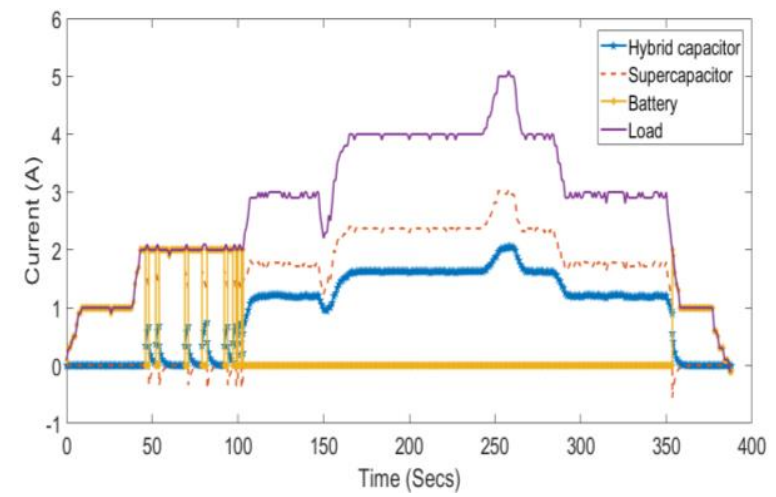

(b)

Figure 8. Response of the energy storage devices under an experimental load profile with (a) individual power controllers and (b) the proposed hybridization topology

\section{CONCLUSION}

In this research, the hybridization of three energy storages battery, supercapacitors and hybrid capacitors is proposed in order to independently exploit the advantages of each of the three energy storage devices. The combination of both supercapacitors and hybrid capacitors is validated from experimental data, therefore electric vehicle manufacturers do not have to be constrained to choosing just either of them, but they can both be combined to take advantage of the high power density and high energy density of the supercapacitor and hybrid capacitor respectively.

Batteries can now become smaller since they do not need to be sized for peak power but strictly for high energy density operations. The prospects of using multiple-input DC-DC converters is also presented and a topology that fits perfectly into the requirements for application in electric vehicles is analyzed. The 
balance point of combining supercapacitors and hybrid capacitors for electric vehicle applications is determined and presented. The proposed hybridization topology is also validated using experimental results from a previous research. The application of the topology proposed in this paper is not limited to only electric vehicles but can be extended to other applications with a similar load profile especially renewable energy applications.

\section{ACKNOWLEDGEMENTS}

This material is based on research/work supported wholly / in part by the National Research Foundation (NRF) of South Africa (Grant Numbers: 112236). The research findings are that of the authors and not that of the NRF.

\section{REFERENCES}

[1] L. Setyawan, et al., "Hybridization of energy storages with different ramp rates in DC microgrids," in 2015 IEEE International Conference on Industrial Technology (ICIT), pp. 1317-1322, 2015.

[2] A. S. Talhar and S. B. Bodkhe, "The global survey of the electrical energy distribution system: a review," International Journal of Electrical and Computer Engineering (IJECE), vol. 9, pp. 2247-2255, 2019.

[3] M. R. B. Khan, et al., "Energy management system for PV-Battery microgrid based on model predictive control," Indonesian Journal of Electrical Engineering and Computer Science (IJEECS), vol. 15, pp. 20-25, 2019.

[4] M. R. B. Khan, et al., "Optimal grid-connected PV system for a campus microgrid," Indonesian Journal of Electrical Engineering and Computer Science (IJEECS), vol. 12, pp. 899-906, 2018.

[5] I. Chotia and S. Chowdhury, "Battery storage and hybrid battery supercapacitor storage systems: A comparative critical review," in 2015 IEEE Innovative Smart Grid Technologies - Asia (ISGT ASIA), pp. 1-6, 2015.

[6] M. A. Zaman and M. H. Rahaman, "Coordinated control of interconnected microgrid and energy storage system," International Journal of Electrical and Computer Engineering (IJECE), vol. 8, pp. 4781-4789, 2018.

[7] I. N. Jiya, et al., "Electrical circuit modelling of double layer capacitors for power electronics and energy storage applications: A review," Electronics, vol. 7, pp. 268, Oct 2018.

[8] F. Akar and V. Bulent, "Battery/UC hybridization for electric vehicles via a novel double input DC / DC power converter," 3rd International Conference on Electric Power and Energy Conversion Systems (EPECS), pp. 3-6, 2013.

[9] A. B. Cultura and Z. M. Salameh, "Modeling, Evaluation and Simulation of a Supercapacitor Module for Energy Storage Application," in Proceedings of the International Conference on Computer Information Systems and Industrial Applications, pp. 876-882, 2015.

[10] V. J. Nagarajah, et al., "Performance analysis of supercapacitors for transportation industry," Indonesian Journal of Electrical Engineering and Computer Science (IJEECS), vol. 13, pp. 1031-1038, 2019.

[11] J. M. J. M. Miller, et al., "Why hybridization of energy storage is essential for future hybrid, plug-in and battery electric vehicles," in 2009 IEEE Energy Conversion Congress and Exposition, ECCE 2009, pp. 2614-2620, 2009.

[12] N. Omar, et al., "Assessment of lithium-ion capacitor for using in battery electric vehicle and hybrid electric vehicle applications," Electrochimica Acta, vol. 86, pp. 305-315, Dec 2012.

[13] S. Pay and Y. Baghzouz, "Effectiveness of battery-supercapacitor combination in electric vehicles," in 2003 IEEE Bologna PowerTech - Conference Proceedings, vol. 3, pp. 728-733, 2003.

[14] D. Stroe, et al., "Accelerated aging of lithium-ion batteries based on electric vehicle mission profile," in 2017 IEEE Energy Conversion Congress and Exposition (ECCE), pp. 5631-5637, 2017.

[15] N. Omar, et al., "Lithium-ion capacitor - Advanced technology for rechargeable energy storage systems," in 2013 World Electric Vehicle Symposium and Exhibition (EVS27), vol. 6, pp. 1-11, 2013.

[16] S. Capacitor, "New product: Energy storage capacitor," News (New Product). [Online]. Available: http://www.samwha.com/capacitor/news/news_product5.aspx.

[17] A. M. Atallah, et al., "Design of photovoltaic, battery/ultracapacitor hybrid power system to electrify minisatellites," in 2016 18th International Middle-East Power Systems Conference, MEPCON 2016 - Proceedings, pp. 670-674, 2016.

[18] A. Gee and R. Dunn, "Novel battery / supercapacitor hybrid energy storage control strategy for battery life extension in isolated wind energy conversion systems," in 45th International Universities Power Engineering Conference (UPEC) 2010, pp. 1-6, 2010.

[19] D. V. Ragone, "Review of battery systems for electrically powered vehicles," SAE Technical Paper 680453, pp. 19, Feb 1968.

[20] V. Aravindan, et al., "Insertion-type electrodes for nonaqueous Li-ion capacitors," Chemical Reviews, vol. 114, pp. 11619-11635, 2014.

[21] I. N. Jiya, et al., "Hybridization of battery, supercapacitor and hybrid capacitor for electric vehicles," in 2018 IEEE PES/IAS PowerAfrica, pp. 19-24, 2018.

[22] JM Energy Corporation, "Lithium ion capacitor ULTIMO," Datasheet. [Online]. Available: http://www.jmenergy.co.jp/pdf/ULTIMO Brocure-en.pdf.

[23] Betta-Batteries, "Lead crystal batteries the power of tomorrow," Datasheet. [Online]. Available: http://www.leadcrystalbatteries.com/media/wysiwyg/NEWDATASHEETS/12V/6_CNFJ-200.pdf. 
[24] H. J. Rautenbach, et al., "Development of smart controller for fuel cell and supercapacitor application in electric vehicles," in 23rd Southern African Universities Power Engineering Conference, 28 - 30 January 2015, pp. 87-92, 2015.

[25] Maxwell.com, "Datasheet K2 ultracapacitors 2.7V series features and benefits," Datasheet. [Online]. Available: http://www.maxwell.com/images/documents/K2Series_DS_1015370_5_20141104.pdf.

\section{BIOGRAPHIES OF AUTHORS}

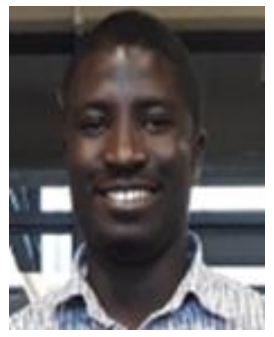

Immanuel Ninma. Jiya was born in Bida, Niger State, Nigeria in 1993. He received the B.Eng. degree in Electrical and Electronic Engineering from the Federal University of Technology, Minna, in 2016. And completed the M. Eng. degree in Electrical and Electronics Engineering at North-West University, Potchefstroom 2520, South Africa in 2018. He is currently continuing his research career with a PhD degree in Electrical and Electronics Engineering at North-West University, Potchefstroom 2520, South Africa. His research current research area is Power Electronics with a special interest for energy storages, economics and management.

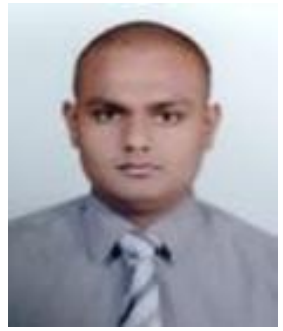

Nicoloy Gurusinghe (M'13) received the B.Sc.(Eng.) degree from University of Moratuwa, Sri Lanka, in 2011 and the Ph.D. degree from the University of Waikato, Hamilton, New Zealand, in 2016. He was a Research Fellow at North-West University, Potchefstroom, South Africa from 2017 to 2018. Since 2018, he has been a Research Associate of Power Electronics at Queen's University Belfast, Belfast, U.K. His research interests include modelling and control of dc-dc converters, supercapacitor applications and energy storage systems for renewable energy applications.

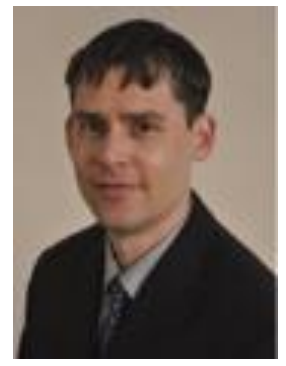

Rupert Gouws holds a Ph.D. degree in Electrical and Electronic Engineering from the NorthWest University (Potchefstroom campus). He consulted to a variety of industry and public sectors in South Africa and other countries in the fields of energy engineering and energy management. He is currently appointed as an Associate Professor specializing in energy engineering, electrical machines and control at the North-West University. The Engineering Council of South Africa (ECSA) registered him as a Professional Engineer and the Association of Energy Engineers (AEE) certified him as a Certified Measurement and Verification Professional (CMVP). 